\title{
"Der Große Ploetz"
}

\author{
Nicolas Le Moigne
}

\section{OpenEdition \\ Journals}

Édition électronique

URL : http://journals.openedition.org/ifha/662

DOI : 10.4000/ifha.662

ISSN : 2198-8943

Éditeur

IFRA - Institut franco-allemand (sciences historiques et sociales)

\section{Référence électronique}

Nicolas Le Moigne, «"Der Große Ploetz" », Revue de I'IFHA [En ligne], Date de recension, mis en ligne le 01 janvier 2006, consulté le 22 septembre 2020. URL : http://journals.openedition.org/ifha/662 ; DOI https://doi.org/10.4000/ifha.662

Ce document a été généré automatiquement le 22 septembre 2020.

(CIFHA 


\title{
"Der Große Ploetz"
}

\author{
Nicolas Le Moigne
}

À l'égal du Duden, du Putzger ou de notre Lavisse, le Ploetz fait partie de ces ouvrages de référence dont l'auteur a connu le rare privilège de devenir un nom commun. En publiant à Berlin en 1863 les Auszüge der alten, mittleren und neueren Geschichte, Carl Ploetz a en effet fourni aux enseignants et aux universitaires un compendium exhaustif et ingénieux. Celui-ci en est désormais à sa 34ème édition, augmentée et complétée, et doublée d'une version sur CD-ROM. Des dizaines de spécialistes y brossent, sur près de 2000 pages, une fresque impressionnante de l'histoire universelle. La forme chronologique générale est accompagnée de nombreux encarts explicatifs, tableaux et organigrammes, à la clarté et à la rigueur irréprochables. L'index, qui s'étend sur près de 200 pages et rassemble près de 100000 entrées, en assure un maniement efficace. Après deux chapitres introductifs sur la préhistoire, la première grande partie est consacrée à l'histoire européenne jusqu'en 1945 ; la deuxième couvre l'histoire des mondes extra-européens jusqu'à la même date ; la troisième, enfin, fait le pari d'une histoire globale à partir de 1945, traitée cependant par aires géographiques. L'ensemble est monumental, et régulièrement mis à jour et enrichi ; il se prête à merveille à la vérification rapide d'un élément factuel, ou à la préparation d'un cours.

Nicolas LE MOIGNE (Lycée Michel-de-Montaigne, Mulhouse) 